\title{
Comparison of Ordinary Medical Care Centers/Partnerships and Practice Clinic in Germany
}

J. Tisonova (Jana Tisonova) ${ }^{1}$, F. Renger (Fabian Renger) ${ }^{2,3}$,

A. Czirfusz (Attila Czirfusz)2

1 Dept. of Pharmacology and Clinical Pharmacology,

Comenius University, Bratislava., Slovakia.

2 St. Elizabeth University, Dept. of Public Health, Bratislava, Slovakia.

3 Medical Care Center, Heidenheim, Germany.

\section{E-mail address:}

czirfusza@gmail.com

\section{Reprint address:}

Attila Czirfusz

St. Elizabeth University

Dept. of Public Health

Nám 1. Maja 1

81000 Bratislava

Slovakia

Source: Clinical Social Work and Health Intervention

Volume: 10

Issue: 3

Pages: $41-49$

Cited references: 17

\section{Reviewers:}

Roberto Cauda

Institute of Infectious Diseases, Catholic University of the Sacred Heart, Rome, IT

Vitalis Okoth Odero

Catholic university of Eastern Africa, Nairobi, KE

\section{Key words:}

Medical Care Center. Usual MCC/ Partnership. Practice Clinic. Exchange of Services. German Medical Assembly. Diagnosis Related Group (DRG). Medical Care Practice. Reimbursement of Budget Overruns. Improved Cooperation.

\section{Key message:}

Managing, controlling and (re-)designing businesses within the system of medical care has become an extremely challenging task. In our paper we analyze the differences between main organizational forms of outpatient care - medical care centers/partnerships and practice clinic model. 


\section{Publisher:}

International Society of Applied Preventive Medicine i-gap

CSWHI 2019; 10(2): 41 - 49; DOI 10.22359/cswhi_10_3_12 @ 2019 Clinical Social Work and Health Intervention

\section{Abstract:}

Objective: Politicians are not the only ones who view medical care centers (MCC) as a model for the future. Even physicians often believe that they are better off with such type of care. However, legal and tax expert Dr. Müller-Kern warns that this is not always true because profits do not increase for every partner and some even experience losses in revenue. This is because disciplines such as strategic planning, marketing, organization theory, quality management or project management run parallel to each other in classical business administration. This is how these disciplines are still taught in schools and universities today.

Aim: Managing, controlling and (re-)designing businesses within the system of medical care has become an extremely challenging task. It is thus better to analyse beforehand whether it is really worthwhile.

Results: In a comparison between the standard MCC/partnership and the practice clinic model, one can see that these are very different structures. Of interest are structures where both forms can be integrated within a single enterprise.

Conclusion: Classic business management, which is based primarily on principles such as linearity, stability and deduction, is less and less capable of answering the burning questions of today's corporate governance. The structure of the German MCC is an excellent type for the medical field and has a very good prospect the next years.

\section{Introduction}

\section{Aspects of the Medical Care Center/ Partnership}

Due to the establishment of enterprises, the salaried physician is considered a co-entrepreneur for tax purposes according to German legislation (Clause 15, $\S 1$, No. 2 of the UStG - Income Tax Act) [1]. Besides the fact that he or she receives income tax-related profit shares and no wages, in terms of VAT (value added tax), the relationship between the MCC (medical care center) partnership and the co-entrepreneurial physician employed should be assessed on the basis of characteristics of the exchange of services within the corporate relationship. The result of the VAT assessment of service relationship depends on whether the physician is effectively self-employed and paid a special rate (fee) or if the service provided by him or her is compensated on the basis of profit and loss. A special rate always exists if the partner receives a fee on a nonshare basis. For example, a special rate exists even if the partner receives a percentage of sales for his or her functions (2).

Essentially, it can be assumed that the physician practices independently because in this case the partner is not subordinate to the enterprise, rather co-determines how 
the enterprise is handled together with the other shareholders [BFH (Bundesfinazhof - Federal Finance Court) 7.12.78, and BStB1 (Bundessteuerblatt - FederalTax Sheet ) II 79,356$)](3,4)$. If the partner-physician provides services to the MCC partnership and these services are only compensated through a profit-sharing percentage independent of services provided, he or she is not considered an entrepreneur. He or she does not engage in taxable transactions and may not bill the enterprise separately for any VAT in connection with his or her services. If he or she does account for VAT for this, he or she owes the corporation pursuant to law - Clause 14, $\S 3$ of the UStG (1). In the absence of entrepreneurial status, the physician may not deduct (5).

Regardless of his or her functions for the MCC partnership, the physician may be considered an entrepreneur if the physician effectively works for him or herself with the intent to generate income in addition to his or her functions for the MCC. If the physician provides services to the $\mathrm{MCC}$ from his own entrepreneurship without receiving a special rate for doing so, these services may be taxable as fictitious services in return for payment pursuant to law - Clause 3, $\S 1 \mathrm{~b}$ of the UStG or other fictitious services pursuant to Clause $3, \S 9$ a of the UStG. $(1,6)$

In the service relationship between the MCC partnership and salaried physician who is not also a partner, the same regulations apply as those for a salaried physician at an MCC corporation. Against the backdrop of the physician's salaried employment, income tax excludes a VAT service relationship between these parties.

If a self-employed contract physician and an MCC partnership come together to form a joint practice without affiliating under company law, an exchange of services exists between these parties that is subject to VAT. This corresponds to the exchange of services between an MCC corporation and a contract physician. Here too, VAT liability exists on the basis of the exchange of services, which supersedes that between the MCC partnership and the patient $(6,7)$.

\section{Dual system for consultants}

In Germany, healthcare is provided both through independent medical practitioners in their own practices (or in a group practice) and in hospitals. This means that a dual system exists in relation to consultants. So there are independent ear, nose and throat practitioners who are self-employed, and ear, nose and throat practitioners who work as employees within a hospital (7-10). This formulation creates the impression that this is something special. In fact, a number of countries have independent GPs who are the first point of call for patients, but no independent consultants. If the GP believes that a consultant should take a look at the ear, he or she sends the patient to hospital and not to an independent colleague. Hospitals do not immediately provide beds for such patients, as they have outpatient departments for such cases. This means that hospital doctors treat both inpatients and outpatients. To this extent the dual system for consultants is unusual.

\section{Organizational forms}

There is a series of different organizational forms $(8,12)$ within outpatient care. A practice is described as a solo practice where there is just one doctor (with support staff) in it. A group practice is made up of multiple doctors who, however, invoice separately. A partnership practice is made up of multiple doctors who invoice together. Doctors who together run a laboratory and share the costs but invoice separately are described as a "collaborative laboratory". In the case of an "equipment-sharing practice", doctors share high-cost equipment. A practice clinic 
offers independent practitioners with a hospital affiliation the infrastructure of a hospital so that these practitioners can lease beds, equipment and staff in order to be able to operate within a hospital.

The term "medical center" relates primarily to the real estate; i.e. a medical center offers independent practitioners practice rooms under one roof with other practitioners. This says nothing as to the degree of cooperation between the practitioners. Some medical centers organize on a joint basis (as for example the disposal of medical waste "Not in the normal waste bins please!"), or purchase from the operator of the medical center, right up to practices that are closely interconnected, where the waiting room and staff are shared so that the boundaries with a group practice are flexible.

Medical care practices (abbreviated as "MVZs" in German) on the other hand offer outpatient care in a range of areas and occupy a special place in the care of outpatients. A medical care practice can be set up as a corporation and can employ practitioners. Any service provider can incorporate the practice. This is particularly attractive for hospitals, which are responsible for setting up about one third of all medical care practices. These enable hospitals to better use their capacity to the full and also to refer patients to themselves via the MCC (in the inpatient department). This of course means that hospitals are then competing with those who, up until now, have made referrals to them - the independent practitioners in the local area - and must be prepared for the independent practitioners to recommend other hospitals to their patients $(8,11)$.

\section{The advantage of the Diagnosis Related Group (DRG)}

In the age of Diagnosis Related Groups (DRGs), identical prices are paid for identical services. This means that, given the same regional average base case and the same DRG, a center offering a full range of healthcare and one offering basic and regular care will achieve the same yield regardless of their costs structure. Germany's independent practitioners generate between 70 to $90 \%$ of their income from services that have been taken over from the statutory health insurance fund $(8,12,13)$. About 70 million German citizens are insured through the statutory health insurance fund $(9,12)$ according to Federal Office of Statistics (6). This makes it the largest health insurance group in Germany by some distance (12), according to Statutory Health Insurance ( $G K V$-Spitzenverband) '(12). It is funded on the contributions principle. This means that insurance payments are funded from contributions received in the same year. If we ignore for the moment the fund law aspects and look for a suitable everyday definition, then an MCC is in fact a larger medical practice in which multiple independent practitioners with different specialties operate together. Some MCCs also have non-medical service providers available, such as physiotherapists and those offering remedial gymnastics and outpatient support services. All this happens in shared spaces at a single location.

Apart perhaps from the names and signage, it would be difficult for a patient to recognize from outside whether this is a medical center, a larger partnership practice or an MCC.

However, significant differences exist compared with traditional practices. If one carries out a closer analysis of an MCC's structure in terms of the law governing funds and compares it with traditional solo or group practices, then considerable differences become evident. While in traditional practices independent practitioners operate on a self-employed basis, an MCC is fundamentally a different construct.

Within the structure of an MCC 
- different forms of incorporation are possible (e.g. GbR [a German company constituted under civil law] or $\mathrm{GmbH}$ [a German limited liability company] etc.),

- it is possible for there to be outside owners,

- partners may operate as doctors or not,

- there is significant scope in terms of regulating succession

- medical "seats" under fund law (accreditations) may lie both with the partners and with the MVZ (the company)

- professional management is (generally) necessary and sensible.

- Health policy environment and general statutory framework

In 2004, the legislator made a fundamental change to the general framework of outpatient care for those covered by statutory health insurance when it first allowed the "medical care practice" form of incorporation under fund law and initiated a dramatic change in the way independent practitioners carry out their profession. The buzz words are the 'opening-up of the markets' and 'increased competition'.

Two laws regulate the activity of MCCs in outpatient care. The management board will be familiar with the content of these laws, as they define the basis and scope of its operations and tasks:

- Statutory Health Insurance Modernization Act ("GMG") in late 2003

- Panel Doctor Law Amendment Act ("PDLA Act") in early 2007

\section{Panel Doctor Law Amendment Act}

A further opening-up of the market (going beyond the licensing of MCCs) was undertaken by the legislature in the (Vertragsarztrechtsänderungsgesetz) German Panel Doctor Law Amendment Act of 2007. Its substantive contents are the licensing of local and regional group practices, the possibility of partial licenses and affiliated practices as well as the extended employment opportunities for doctors. In addition, the legislature made it possible for medical service providers to be remunerated directly via a direct contractual relationship with health insurance funds. In the context of the "direct contracts", it has become possible to bypass the Panel Doctor Associations "kassenärztlicheVereinigungen" or "KV" of GPs treating members of a health (Panel Doctor insurance scheme.) as the organization arranging settlement of payments. The boundaries between inpatient and outpatient care have also been designed to be flexible.

The provisions of the Panel Doctor Law Amendment Act ("PDLA Act") approved by the German Bundestag on 27 October 2006 in a second/third reading have applied since 1 January 2007 and continue to do so. This law affects, among other things, the amendments to the draft professional regulations for psychotherapists already adopted at the 7th German Psychotherapists' Conference in Dortmund on 13 January 2006, and opens up the latter's application to professional work within statutory health insurance. At the same time, the primary objectives of the new statute consist of ameliorating regional care issues by relaxing the law governing forms of incorporation and making these more flexible, as well as designing panel psychotherapy services in a way that is more efficient and hence more competition-based.

In particular, in view of the growing competition pressure from medical care practices (MCCs) an extension of the organizational and commercial forms of incorporation open to individual panel psychotherapists has been announced. It was also intended to remove ambiguities in relation to the conditions precedent to the setting-up of MCCs. The extent to which these goals were implemented within the area of 
psychotherapy is intended to be set out and commented on below.

The most important new regulations concern

- the retirement age for those working as panel psychotherapists,

- the age limit for access to work as a panel doctor,

- the appointment of psychotherapists with no numerical limit in open and restricted planning areas,

- work elsewhere (secondary business premises/setting-up of branches),

- local and regional group practices (partnership practice),

- partial licenses,

- $\quad$ second jobs at a hospital and

- the regulations governing the MCC (4, 12).

In license-restricted areas the existing owners of practices or their heirs no longer have a free choice as to a panel practice's successor, and are not free simply to negotiate the purchase price with the latter. This applies in any case where there is no successor available who has a license covering the restricted area in which the practice to be transferred is located.

Specifically in the context of a successor appointment process, the panel doctor's position must then be put out for tender by the panel doctor association and filled by the licensing committee with an applicant who is to be selected "using its proper discretion" (13). The legislator has formulated the successor appointment process in a way that is by no means comprehensive. When making the resulting necessary interpretation of the statutory provisions, one has to take into consideration the fact that the successor appointment process was also introduced in order to make it possible for the owner of a panel practice to realize its commercial value and thereby to preserve the fundamentally protected acquired rights of the panel doctor in restricted areas $(7,15)$.

Despite numerous attempts to achieve comparability between hospitals in terms of medical standards, for patients there remains a lack of transparency as far as the hospitals market is concerned. But in order to be able to give their consent, patients need information $(8,15)$. For individual cities such as Berlin and Hamburg as well as for regions such as the Rhine-Ruhr Area, clinic guides are in place or are being prepared. But to date, these relate only to a small selection of conditions. The same applies to quality reports which clinics have for years been obliged to publish. For the medical laity (i.e. for virtually all patients), their information content is rather small, however, as they are aimed at the "Diagnosis Related Groups" (DRGs) that are crucial for payment settlement $(9,16)$.

For the independent doctor, budgeting means that his/her services are subject to a fixed financial framework. He/she receives a standard volume of work so that within a set period a billable volume of panel-doctor services are to be paid for at the prices included in the Euro Fee Regulation [Euro-Gebührenordnung] and applicable to the doctor or doctor's practice." $(8,9,12$, 14).

\section{Comparison of MCCs and practice clinics}

The following figure (Fig 1) shows a comparison between the standard MVZ/ partnership and the practice clinic model.

If we regard the setting-up or operation of a medical care practice ("MCC") as a process that has to clear certain obstacles, then the specific funding issues are normally not discussed in the initial phase of such a project. In some MCC projects this can lead to problems which can subsequently be extremely costly to remove. Thus establishing the legal form of the 
Figure 1: Comparison of MVZs and practice clinics

\begin{tabular}{|l|c|c|}
\hline & \multicolumn{1}{|c|}{ MCCs } & \multicolumn{1}{|c|}{ Practice clinics } \\
\hline Legal form & $\begin{array}{l}\text { GbR [a German company } \\
\text { constituted under civil law] / } \\
\text { partnership }\end{array}$ & $\begin{array}{l}\text { GmbH [limited liability com- } \\
\text { pany]/AG [company limited } \\
\text { by shares] }\end{array}$ \\
\hline Number of employees & 40 & double-digit \\
\hline Average no. of patients a day & $40-100$ & $30-80$ \\
\hline Doctors employed & $2-5$ & $4-8$ \\
\hline
\end{tabular}

\section{Source: (9)}

MCC early on can have long-term consequences for subsequent project-funding options $(9,12,13)$

Independent practitioners' grounds for selecting the form of cooperation within an MCC are broadly categorized:

- the exercise of their profession within an employee/employer relationship (in the case of doctors willing to set up a business, this may be in preparation for their becoming self-employed),

- the possibility of flexible working hours,

- provision for old age through the sensible disposal of the practice,

- the future investment potential,

- the realization of economies of scale,

- the realization of economies of scope,

- the possibility of agreeing mutual reimbursement of budget overruns,

- joint marketing,

- professional management,

- a good starting position for integrated care contracts,

- market strength when competing with other practitioners, special interest groups and hospitals,

- improved cooperation with other healing professions and with the inpatient sector.
From the point of view of a hospital, the setting-up of an MCC facilitates improved cooperation with the outpatient sector:

- the achievement of additional income via MCC profits,

- the improvement of the competition situation compared with competitors in the inpatient sector,

- the restructuring and extension of a hospital's range of services on offer to date,

- increased cooperation with independent practitioners for the purpose of improving patient care.

The circle of those service providers who are entitled to set up practices extends far beyond independent practitioners and hospitals. The personal, commercial and competition-related reasons set out should again be seen here against the background of the relevant starting position for the service provider, e.g. in the cases of pharmacists, healthcare professionals, psychotherapists, pension funds and rehabilitation facilities. The basic starting point here is the improvement of the market and sales situation through closer integration with medical services provision and a greater emphasis on service at the patient level $(9,12,17)$. 


\section{Procedural improvement}

The professions are becoming increasingly specialized - which sometimes means problematic new points of intersection for patients. This tends to lead to further fragmentation of patient care and of the roles of the professions. However, disruptions in care and unnecessary waiting times do not result only from the pressure to rationalize and reduce costs but also from the fact that measures could be better coordinated $(9,12,17)$.

\section{Conclusion}

In a comparison between the standard $\mathrm{MCC} /$ partnership and the practice clinic model, one can see that these are very different structures. Of interest are structures where both forms can be integrated within a single enterprise.

\section{References:}

1. https://www.gesetze-im-internet.de.

2. ANONYMUS (2014) Resolutions for the agenda intem VII: Progress Report of the German Medical Association. DtschArztebl. vol 111 (25): A-1157/B-997/C-941, URL: http://www.aerzteblatt.de/archiv/160833/ Entschliessungen-zum-Tagesordnungspunkt-VII- Taetigkeitsbericht-der-Bundesaerztekammer, (last accessed: 15.07.2014).

3. http://www.bundessteuerblatt.de.

4. https://www.bundesfinanzhof.de.

5. ZIMMERMANN R, HOTTMANN J, KIEBELE S ET AL. (2017) The partnership company in tax legislation: Practical Guide Achim, Germany, EFV, 12th edition, 1499p. ISBN 978-3-8168-4082-4.

6. ANONYMUS (2014) Mini-MCC: No requirement for employment of full-time physicians, URL:http://pwk-partner.de/aktuelles/2012-07/mini-mvz-keine- notwendigkeit-der-anstellung-von-vollzeit-beschaeftigter-aerzte.

7. RENGER F, CZIRFUSZ A (2015) Refining the Typology of Ordinary Medical Treatment
Centers/ Partnerships, IJAMSGD (International Journal for Applied Management Science and Global Developments), Wiesbaden, C2-1-10, ISSN: 2195-4135.

8. RENGER F, CZIRFUSZ A (2015) Management Aspects of the Effects of Medical Care Centers (MCC) on the German Health Care System, JISRAKI (Journal of Inter-Systems Research and Applied Knowledge Interaction), Wiesbaden, C3[1-5], ISSN: 21979146.

9. RENGER F, CZIRFUSZ A (2015) Comparison of Practice Clinic/ Standard Medical Care Center/ Partnership in Terms of their Typological Aspects, IJAMSGD (International Journal for Applied Management Science and Global Developments), Wiesbaden, C7[1-8], ISSN: 2195-4135.

10. WINKELHAKE O (2011) Ambulatory Health Care in Germany, RheinAhrCampus, Remagen, requested on 24.11.2011.

11. WERNITZ M H, PELZ J (2011) Health economics and the German healthcare sector - a practical oriented coursebook for study and career, Kohlhammer, Stuttgart, 240p, ISBN-10: 3170215647.

12. CZAJA M (2011) Business-related Chances and Risks of the modell Practice Clinic for the specialist physician. In: Wildauer Series, Volume 7, BWV Berliner Wissenschaftsverlag, Wildau Berlin, 91p. ISBN-10: 3830519370. ISBN-13: 978- 3830519379.

13. FRIELINGSDORF O (2009) Professional Leadership of MCC, C.H.Beck., Ecomed Landsberg, 1. Ed, 357p. ISBN 9783609515632.

14. ANONYMUS (1988) Social Code - Book $V$ - Statutory Health Insurance (Sozialgesetzbuch (SGB) - Fünftes Buch (V) - Gesetzliche Krankenversicherung), Bundesgesetzblatt, Part I (photocopy), 1988-1229, No. 62, pp. 2477-2597, ISN: DEU1988-L-43202.

15. KLAPP E (2006) Opportunities and Risks in closed areas, In: Release and Aquisition of a medical practice,Abgabe und Übernahme 
einer Arztpraxis, Springer Verlag Berlin Heidelberg, 23-44, ISBN 978-3-540-256892, Online ISBN 978-3-540-30423-4.

16. BRAUN-GRUENEBERG S, WAGNER $\mathrm{K}$ (2009) Clinics in patient perception, In: Reinhold Roski : health communication in a coprehensible form: Participants - Audi- ence, VS Verlag fur Sozialwissenschaft, pp. 220-221. ISBN 978-3-531- 15907- 2.

17. http://www.kvhessen.de/fileadmin/media/documents/Mitglieder/Neue_Versorgungs-formen /MVZ/KBV_Publikation MVZ_Bausteine.pdf, (Last updated on: 31/03/2015) . 